\title{
Risky sexual behavior and associated factors among grade 9-12 students in Humera secondary school, western zone of Tigray, NW Ethiopia, 2014
}

\author{
Abel Fekadu Dadi ${ }^{1, ~}$, Fiseha Gebrethadkan Teklu \\ ${ }^{1}$ Gondar University, College of Medicine, Institute of Public Health, Department of Epidemiology and Biostatistics, Gondar, Ethiopia \\ ${ }^{2}$ Humera Town Woreda Health Office, Humera, North West Ethiopia
}

\section{Email address:}

Fekten@yahoo.com (A. F. Dadi), fisehagtw.1980@yahoo.com (F. G/thadkan)

\section{To cite this article:}

Abel Fekadu Dadi, Fiseha Gebrethadkan Teklu. Risky Sexual Behavior and Associated Factors among Grade 9-12 Students in Humera Secondary School, Western Zone of Tigray, NW Ethiopia, 2014. Science Journal of Public Health. Vol. 2, No. 5, 2014 , pp. 410-416. doi: $10.11648 /$ j.sjph.20140205.16

\begin{abstract}
Introduction: About 1.7 billion people which is more than a quarter of the world's population were between the ages of 10 and 24, and $86 \%$ are living in less developed countries. The World Health Organization (WHO) defines adolescent people as those between the ages of 10 to 19 years. Across the life span, adolescence is the time of greatest risk taking. Even though, adolescent risk taking can derive them to development, it more results in experiencing risky sexual behavior like contracting sexual transmitted diseases and unwanted pregnancy than disease. This age category were highly predominant in secondary schools in which government attention is very crucial. Objective: To assess, risky sexual behavior and associated factors among grade 9-12 students in Humera town, western zone of Tigray, NW Ethiopia. Methodology: Institutional based cross-sectional study was conducted. Simple random sampling technique was used to select a sample of 422 participants. A structured, pretested and self-administered questionnaire was used to collect data. Collected data was entered and analyzed using SPSS version 16. Crude and adjusted odds ratio with its confidence interval was used as measure of association and to assure stastical significance. Result: All of the respondent were included in the study. The overall prevalence of risky sexual behavior was $13.7 \%(95 \% \mathrm{CI}: 10.6 \%, 16.8 \%)$ and it is predominant among the males. Factors like not living with family [AOR=3.22,95\%CI:1.29-8.02], being male [AOR=17.17,95\%CI:4.55-64.75], experiencing peer pressure $[\mathrm{AOR}=2.27,95 \% \mathrm{CI}: 2.79-15.89]$ and not participating in any religious education $[\mathrm{AOR}=6.17$, 95\% CI: 2.24-17.16] were the factors that increase the odds of practicing risky sexual behavior and not exposed to pornographic movie is a factor that prevent [AOR $=0.36,95 \% \mathrm{CI}$ : $0.32-0.91$ ] the odds of practicing risky sexual behavior among the students. Conclusion: Considerable proportion of students were engaged in risky sexual behavior. Sex, participation in religious education, living with parents, peer pressure and looking porno graphic movies were associated with risky sexual behavior. Any interventions that can affect the above risk factors may be helpful to protect adolescent's health in school.
\end{abstract}

Keywords: Risk Sexual Behavior, Cross Sectional Study, High School Student

\section{Introduction}

The World Health Organization (WHO) defines adolescent people as those between the ages of 10 to 19 years [1]. Today's adolescent and young adults constitute the largest cohort ever to enter the transition to adulthood. Evidence showed that nearly half of the global population were less than 25 years old and nearly $90 \%$ live in developing countries. About 1.7 billion people of the world's population were between the ages of 10 and 24[2].These teenagers are tomorrow's parents[3]. Adolescents are at high risk for practicing risky sexual behaviors[4]. Across the life span, adolescence is the time of greatest risk taking[5].

While sexual behavior in adolescence can be risky, it is also a natural part of human development[6]. Even though, adolescent risk taking can derive them to development, it more results in experiencing risky behavior than disease[7]. Risky sexual behavior is any behavior that increase the 
probability of negative consequence associated with sexual contact like sexually transmitted disease like HIV, unplanned pregnancy and abortion which can lead them to death and disability. It also includes behaviors like having multiple partners, early sexual initiation and failure to discuss risk topics with partner and inability to use protective methods like condom [8].

Worldwide, risky behaviors related to sexual practice in adolescent people have taken much of the attention. Even though the proportion of adolescents who delay sexual onset and use condom have increased worldwide a great deal of risky sexual behavior continues[9]. Because of this, adolescents experience a large number of unplanned pregnancies and sexually transmitted disease including HIV/AIDS[10].

Report from USA showed that $46 \%$ of in school youths had ever had sexual intercourse and $34 \%$ had sexual intercourse during the previous three months. From this, thirty nine percent did not use condom last time they had sex and seventy seven percent did not use any birth control to prevent pregnancy the last time they had sex with their opposite sex. About $14 \%$ had sex with four or more people during their life $[11,12]$.

Current statistics on HIV/AIDS indicate that one-half of all new HIV infections worldwide occur among young people ages 15 to 24 . Every minute, five young people worldwide become infected with HIV/AID[4]. SubSaharan Africa remains most severely affected with nearly 1in every 20 adults $4.9 \%$ living with HIV and accounting for $69 \%$ of the people living with HIV worldwide[13]. Different studies also revealed that adolescents in Sub Saharan Africa were also tend to engage in having multiple sexual partner, concurrent sexual partners and unprotected sexual intercourse[14-16].

In Ethiopia comprising $30 \%$ of the population, adolescents in the age range of 15-24, represent a huge segment of potentially vulnerable population in Ethiopia and an increasing number of them are involved in unsafe sexual practices and hence face undesired health outcomes such as unplanned pregnancy, too early childbirth, unsafe abortion and sexually transmitted disease[15]. There are evidences that show that some adolescents, who are left in the care of siblings without consistent adult supervision, have increased opportunities for sexual activity[17].

Different findings in different area reports magnitude of risky sexual behavior in the range of $21.6 \%$ to $42.1 \%$ as measured by having multiple sexual experience [18-21]. Living with parents [19-26], peer pressure/influence[19, 21, 27-29], Sex[20, 26, 30], family income[31, 32], participation in religious activity[18, 33], looking pornographic movies[34, 35], substance use like alcohol, chat and different drugs[8, 18-20, 26, 31, 36], early initiation of $\operatorname{sex}[7,30]$, family income[19, 35] were reported as a risk factor for practicing risky sexual behavior.

Mapping these risk factors is complicated by inconsistency among studies. Researchers in different papers define "risky sexual behavior" in different ways.
Different studies consider risky sexual behavior as a single behavior while it is should be considered as a combined practice of different risky practices[37]. Such studies are limited in the country as well as in the study area. So this study is mainly intended to assess the magnitude and risk factors associated with risky sexual behavior taking combination of four practices among adolescents in grade 9 to 12 students in humera town secondary school, North West Ethiopia.

\section{Methods}

\subsection{Study Design, Population and Period}

Institutional based cross sectional study design was employed from February to April 2014 at humera town, Tigray, North West Ethiopia. Humera town is located at 1,373 kilometers away from Addis Ababa. The total number of younger population in the town is estimated to be 7,845 , out of which $27 \%$ of the total population is considered as adolescent. There are two secondary schools in the town. All students registered for grade $9-12$ in the age category of $14-19$ were included in the study. Severely ill students and students who are dropped out from the school in the mid-year were excluded.

\subsection{Sample Size Determination}

The sample size was calculated using a single population proportion formula by considering the proportion of risky sexual practice as $50 \%$ and $5 \%$ margin of error.

$$
\mathrm{n}=\frac{(\mathrm{Z} \alpha / 2)^{2} \mathrm{P}(1-\mathrm{P})}{\mathrm{d}^{2}}
$$

Where:

$\mathrm{n}=$ Sample size required

$\mathrm{Z} \alpha / 2=95 \%$ confidence level (1.96)

$\mathrm{P}=$ Proportion of adolescents $(0.5)$

$\mathrm{d}=$ Desired precision $(5 \%)$

Different risk factors were considered for calculating the sample size and finally the largest sample size was considered. Considering a $10 \%$ non-response rate the final sample size was found to be 422 .

\subsection{Sampling Technique and Procedure}

First students in the school were stratified by their grade. Currently there were 3214 students in the two schools. List of students of grade 9 to 12 was prepared and used as a sampling frame. Sample size was allocated for every strata based on proportional allocation to their size. Finally students from every class were selected by simple random sampling through computer generated numbers.

\subsection{Operational Definition}

Adolescents: Students who are between the ages of 14 19 years old. 
Lifetime sexual partner: refers to the number of sexual partners a student could have till the survey.

Sexually active: Students who claimed to have engaged in sexual act at least once prior to the study.

Secondary school: according to educational cycle of Ethiopia, it included grade 9, grade10, grade11 and grade 12.

Risky sexual behavior: a student is considered as practicing risky sexual behavior if he/she practice at least one of the following

- Multiple sexual partner- Having more than one sexual partner until the survey

- Early initiation of sex - sexual debut at the minimum age of 18 years old.

- Inconsistent use of condom - Incorrect use or fail to use condom at least ones during sexual intercourse until the survey

- $\quad$ Sex with commercial sex workers - Sexual act with commercial sex workers at least ones until the survey

- Participation in religious education- attending religious education given in religious organizations until the survey.

\subsection{Data Collection and Processing}

A quantitative data was collected using a standardized pre-tested self-administered interview by adopting sexual and Reproductive Health (SRH) questioner of World Health Organization to local based scenario. Questioner was originally in English and then translated to local language, Tigrigna and back to English for consistency. The questioner was used to collect data after being pretested in schools outside the study area. Experienced facilitators were selected and trained prior to the survey.

\subsection{Data Quality Management and Analysis}

Data collected from the questioner was cleaned and entered to Epi info version 3.5.1 and exported to SPSS version 16 for further analysis. Frequency, percentage, mean and standard deviation was used to data description. Tables and figures were used to present the data. Double entry was performed to assure the quality of the data. Both $\mathrm{Bi}$ variable and multi variable logistic regression was used to identify possible factors associated with the outcome. Adjusted odds ratio with its $95 \%$ confidence interval was used to report stastical significance. Hosmer and lemeshow goodness of fit test was used to evaluate model fitness.

\subsection{Ethical Consideration}

Ethical clearance was obtained from Institutional review board of University of Gondar. Permission to conduct was obtained from local government and school director. For students age less than 18 written consent was obtained from their parent through sending the letter to them at home and assent was also obtained from the students as well. All the information obtained from the respondent was anonymous and confidential.

\section{Results}

\subsection{Socio- Demographic Characteristics of the Respondent}

Table 1. socio-demographic characteristics of respondents among grade 9-12 in Humera secondary school, Tigray NW Ethiopia, May2014 ( $n=422)$

\begin{tabular}{|c|c|c|}
\hline Characteristics & Frequency & Percent $(\%)$ \\
\hline \multicolumn{3}{|l|}{ Sex } \\
\hline Male & 253 & 60 \\
\hline Female & 169 & 40 \\
\hline \multicolumn{3}{|l|}{ Age } \\
\hline$<18$ years & 267 & 63.3 \\
\hline$>18$ years & 155 & 36.7 \\
\hline \multicolumn{3}{|l|}{ Religion } \\
\hline Christian & 396 & 93.8 \\
\hline Muslim & 26 & 6.2 \\
\hline \multicolumn{3}{|c|}{ Participation in Religious Education } \\
\hline Yes & 210 & 49.8 \\
\hline No & 212 & 50.2 \\
\hline \multicolumn{3}{|l|}{ Ethnic group } \\
\hline Tigrai & 387 & 91.7 \\
\hline Others & 35 & 8.3 \\
\hline \multicolumn{3}{|l|}{ Marital status } \\
\hline Unmarried & 403 & 95.5 \\
\hline Married & 15 & 3.6 \\
\hline Divorced & 4 & .9 \\
\hline \multicolumn{3}{|c|}{ Respondent level of Education } \\
\hline $9^{\text {th }}$ & 182 & 43.1 \\
\hline $10^{\text {th }}$ & 149 & 35.3 \\
\hline $11^{\text {th }}$ & 50 & 11.8 \\
\hline $12^{\text {th }}$ & 41 & 9.7 \\
\hline \multicolumn{3}{|c|}{ Currently living with parents } \\
\hline Yes & 325 & 77 \\
\hline No & 97 & 23 \\
\hline \multicolumn{3}{|l|}{ Family income Et Birr } \\
\hline$<1000$ & 159 & 37.7 \\
\hline $1000-2000$ & 116 & 27.5 \\
\hline$>2000$ & 147 & 34.8 \\
\hline \multicolumn{3}{|l|}{ Father educational Level } \\
\hline Unable to read and write & 46 & 10.9 \\
\hline Able to read and write & 198 & 46.9 \\
\hline Grad 4-8 & 93 & 22 \\
\hline Grad 9-12 & 60 & 14.2 \\
\hline Above 12 grad & 25 & 5.9 \\
\hline \multicolumn{3}{|l|}{ Mother educational Level } \\
\hline Unable to read and write & 147 & 34.8 \\
\hline Able to read and write & 172 & 40.2 \\
\hline Grade $4-8$ & 75 & 17.8 \\
\hline Grade $9-12$ & 23 & 5 \\
\hline Above 12 grade & 5 & 1.2 \\
\hline
\end{tabular}


All the study participants were fill the self-administrated questioner. Among the participants 253(60\%) were male. The mean age of respondents was $16.89(S D \pm 1.16)$. Among participants $91.7 \%$ were Tigrean in ethnicity and $396(93.8 \%)$ were Christians. One hundred eighty two (43.1\%) of the study participant's level of education was grade 9 . One hundred ninety four $(47 \%)$ of the participants were whom their fathers had able to read and write, and $169(40.9 \%)$ of the respondents were whom their mothers able to read and write. Three hundred twenty-five (77\%) of the study participants were living with their parents (table 1).

\subsection{Sexual Behavior}

Table 2. -Risky sexual behavior of the study participant until the time of the survey among students in grade 9-12, humera secondary school, tigray NW Ethiopia, may 2014(N=422)

\begin{tabular}{lcl}
\hline Characteristics & Frequency & Percent (\%) \\
\hline Risk Sexual Practice & 58 & 13.7 \\
Yes & 364 & 86.3 \\
No & & \\
Have you ever had sexual intercourse & 21.8 \\
Yes & 92 & 78.2 \\
No & 330 & \\
Perceived experiencing peer pressure & 26.8 \\
Yes & 113 & 73.2 \\
No & 309 & \\
Have you ever seen pornographic movie & 39.1 \\
Yes & 165 & 60.9 \\
No & 257 & \\
Discussion with parents on sexual matters & \\
Yes & 181 & 4.9 \\
No & 241 & 51.9 \\
Have you ever consumed alcohol & & \\
Yes & 203 & \\
No & 219 & \\
Have you ever smoke cigarette & & \\
Yes & 386.1 \\
No & 414 & \\
Chew chat & & \\
Yes & & \\
No & & \\
\hline & & \\
\hline
\end{tabular}

Ninety two $(21.8 \%)$ of the participants reported as they had ever sex prior to the survey. One hundred thirteen respondents reported as they had experience of peer pressure prior to the survey (Table 2).

\subsection{Prevalence of Risky Sexual Behavior and Associated Risk Factors}

This study revealed that the prevalence of risky sexual behavior among grade 9-12 students in humera town was found to be $13.7 \%$ (95\% CI: $10.6 \%, 16.8 \%)$. High proportion of males $(93.1 \%)$ practice risky sexual behavior.

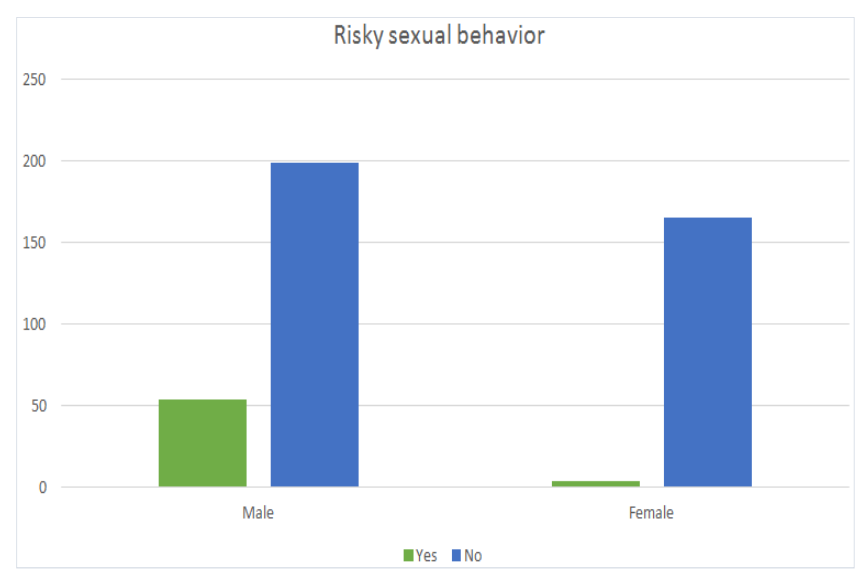

Fig 1. Prevalence of risky sexual behavior and sex variation among students of grade 9-12 in humera town secondary school, tigray $\mathrm{NW}$, Ethiopia $(N=422)$

\subsection{Factors Associated with Risky Sexual Behavior}

Multivariable logistic regression analysis was done to identify the effect of independent factors after controlling other confounding variables. The overall model to predict the probability of risky sexual behavior was statistically significant $(\mathrm{P}<0.001)$ and the overall prediction of the model was $92 \%$. After controlling confounding effect of different variables, exposure factors like sex, participation in religious education, living with parents, having peer pressure, and saw pornographic films were significantly associated with risky sexual behavior.

Accordingly males were 17.1 [AOR=17.1, 95\%CI: 4.5564.75] times more likely to practice risky sexual behavior than females. Living with parents does have also significant association with risky sexual practice and those who were not living with their parents were found to be 3.22 [AOR=3.22, 95\%CI: 1.29-8.02] times more likely to practice risky sexual behavior than those who were living with their parents.

Participation in religious education was also found to have significant association with risky sexual behavior and those who were not participate in religious education were found to be 6.17 [AOR=6.17, 95\%CI: 2.24-17.16] times more likely to practice risky sexual behavior than those who were participate.

More over peer pressure was also significantly associated with risky sexual practice. Students who were report as having peer pressure were found to be 6.66 [AOR=6.66, 95\% CI: 2.79-15.89] times more likely to practice risk sexual behavior than students who did not had.

The other variable which had significant association with the risk of sexual behavior was exposure to pornographic movie. Students who did not have exposure to pornographic movies were 0.36 [AOR $=0.36(0.32-0.91)]$ times less likely to practice risky sexual behavior than those who had exposure (Table 3). 
Table 3. Bi-variable and multivariable analysis of factors associated with risky sexual behavior among grade 9-12 students in Humera secondary school, Tigray ,NW Ethiopia, May2014(N=422)

\begin{tabular}{|c|c|c|c|c|}
\hline \multirow{2}{*}{ Characteristics } & \multicolumn{2}{|c|}{ Risky sexual practice } & \multirow{2}{*}{$\operatorname{COR}(95 \% \mathrm{CI})$} & \multirow{2}{*}{$\operatorname{AOR}(95 \% C I)$} \\
\hline & Yes & No & & \\
\hline \multicolumn{5}{|l|}{ Sex } \\
\hline Male & $54(34.8)$ & 199(54.7) & 1 & 1 \\
\hline Female & $4(23.2)$ & $165(45.3)$ & $0.89(0.32-0.25)$ & $17.17(4.55-64.75)^{* *}$ \\
\hline \multicolumn{5}{|c|}{ Participate in religious Education } \\
\hline Yes & $9(15.5)$ & $201(55.2)$ & 1 & 1 \\
\hline No & $49(84.5)$ & $163(44.8)$ & $6.71(3.20-14.07)$ & $6.17(2.24-17.16)^{* *}$ \\
\hline \multicolumn{5}{|l|}{ living with family } \\
\hline Yes & $34(58.6)$ & $24(41.4)$ & 1 & 1 \\
\hline No & 291(79.9) & $73(20.1)$ & $2.81(1,57-5.04)$ & $3.22(1.29-8.02)^{* *}$ \\
\hline \multicolumn{5}{|l|}{ Get pocket money } \\
\hline Yes & $54(93.1)$ & $249(68.4)$ & $6.24(2.21-17.63)$ & \\
\hline No & $4(6.9)$ & $115(31.6)$ & 1 & \\
\hline \multicolumn{5}{|l|}{ Peer pressure } \\
\hline No & $34(58.6)$ & $78(21.7)$ & 1 & 1 \\
\hline Yes & $24(41.4)$ & $285(78.3)$ & $0.19(0.11-2.35)$ & $6.66(2.79-15.89)^{* *}$ \\
\hline \multicolumn{5}{|c|}{ See pornographic movie } \\
\hline Yes & $44(75.9)$ & $121(33.2)$ & 1 & 1 \\
\hline No & $14(24.1)$ & $243(66.8)$ & $0.16(0.12-0.84)$ & $0.36(0.32-0.91)^{* *}$ \\
\hline \multicolumn{5}{|c|}{ Discussion with parents } \\
\hline Yes & $12(20.7)$ & $169(46.4)$ & 1 & \\
\hline No & $46(79.3)$ & $195(53.6)$ & $3.32(1.70-6.48)$ & \\
\hline \multicolumn{5}{|c|}{ Have you ever drink alcohol } \\
\hline Yes & $43(74.1)$ & $160(44)$ & $3.66(1.96-6.82)$ & \\
\hline No & $15(25.9)$ & 204(56) & 1 & \\
\hline \multicolumn{5}{|l|}{ Smoking cigarette } \\
\hline Yes & $4(6.3)$ & $4(1.1)$ & $6.68(1.62-27.45)$ & \\
\hline No & $54(93.1)$ & $360(98.9)$ & 1 & \\
\hline \multicolumn{5}{|l|}{ Chat chewing } \\
\hline Yes & $22(37.9)$ & $14(3.8)$ & $15.28(7.18-32.43)$ & \\
\hline No & $36(62.1)$ & $350(96.2)$ & 1 & \\
\hline
\end{tabular}

** Significant at $\mathrm{p}$-value $<0.05$

\section{Discussion}

This study provides insight in to the prevalence and risk factors associated with risky sexual behavior using composite practices among grade 9-12 students in humera town.

The finding of this study showed that $13.7 \%$ (95\% CI: $10.6 \%, 16.8 \%$ ) of the students have had practice risky sexual behavior prior to the survey. This prevalence is lower than studies conducted elsewhere [18-21]. This difference might be due to the approaches taken to quantify risky sexual behavior. This study tried to consider four different risky practices to measure the students over all risky sexual behavior while the other studies only contemplate single factor.

Student's sex is significantly associated with risky sexual behavior. In this study male students have the higher odds of practicing risky sexual behavior as compared to female students. This result is supported by different study conducted in Ethiopia [20, 26, 30].
Participation in religious education is protective factor for risky sexual behavior. In this study students who did not participate in any religious education were at higher odds of practicing risky sexual behavior. This result is consistent with both qualitative and quantitative findings in different area[18, 33]. Study of youth's age in USA found that attending religious services identified "moral, values and religious beliefs" as the factor that most affect their decision to practice risky sexual behaviors. Here the degree of participation may vary by the frequency and other factors.

Significant number $(77 \%)$ of students reported as they were lived with their parents. This study was tried to explore the relationship of living with family and the degree of practicing risky sexual behavior and found significant association. This is also in line with study conducted before [19-26]. This can be explained by parent adolescent close supervision can help in avoidance or lower practice of risky sexual behavior and other factors that can lead to risky sexual behavior.

This study further declared that students who have report as having peer pressure were more than 6 times at higher 
odds of practicing risky sexual behavior as compared to who did not had. This is similar with other studies before [19, 21, 27-29]. This might be due to the fact that adolescents are at higher probability of sharing their day to day life experience and they take majority of their time with their friends especially in students those were not live with their families.

More over this study was also revealed that exposure to pornographic movie put the students at higher risk of practicing risky sexual behavior. Those students who report their exposure to pornographic movie were 2.77 times more likely to undertake risky sexual behavior and this is supported by different studies conducted before[34, 35].

The strength of this study is its application of composite risky behaviors together to measure student's risky sexual behavior. This can clearly indicate the burden of this misbehavior among sexually active students at this school. Additionally even though it was tried to minimize social desirability bias through administration of self-administered questioner, stile because of sensitive nature of the problem, the possibility of underestimation cannot be ruled out.

\section{Conclusion and Recommendation}

This study has shown that a considerable proportion of students were engaged in risky sexual behavior. Factors like not living with family, exposed to pornographic movies, being male, experiencing peer pressure and not participating in any religious education were the factors that increase the odds of practicing risky sexual behavior among the students. Any interventions that can affect the above risk factors may be helpful to protect adolescent's health in school.

\section{Competing Interest}

Authors declare that they have no competing interest.

\section{Acknowledgement}

The authors would like to thank data facilitators and respondents for their patience and provide valuable response. And also different administrative bodies and teachers in humera town secondary school for their support and facilitating the field works.

\section{References}

[1] Seme A and Wirtu D: Premarital Sexual Practice among School Adolescents in Nekemte Town, East Wollega. Ethiop.J.Health Dev, 2008. 22(2).

[2] UNFPA the state of world population, "People and possibilities in a World of 7 billion. 2011.

[3] Dawud A: Perception of the risks of sexual activities among out-of school adolescents in South Gondar Administrative Zone, Amhara Region. June 2003.
[4] Alamrew Z, Bedimo M, and Azage M: Risky Sexual Practices and Associated Factors forHIV/AIDS Infection among Private College Students in Bahir Dar City, Northwest Ethiopia. ISRN Public Health, 2013.

[5] Chick C.F and Reyna V.F: A fuzzy trace theory of adolescent risk taking: Beyond self-control and sensation seeking. The Adolescent Brain, American Psychological Association, 2012: p. 379-428.

[6] Guttmacher Institute. Facts on American teens' sexual and reproductive health. Retrieved from http://www.guttmacher.org/pubs/FB-ATSRH.html\#1. (2012, February).

[7] Institute of Medicine \& National Research Council. The science of adolescent risk-taking: Workshop report. Committee on the Science of Adolescence. Washington, DC: The National Academies Press. 2011.

[8] Cooper ML: Alcohol use and risky sexual behavior among college students and youth evaluating the evidence. Journal of studies on alcohol 2002. 14(14): p. 101-117.

[9] Trends in sexual risk behavior among high school students United State,1991-1997, morbidity and mortality report. 1998. 47(36): p. 749-752.

[10] National Academy Press, Inistitute of Medicine, The hidden epidemic: confronting sexually transmitted disease, Washington, DC: . 1996.

[11] Sexual risk behavior :HIV,STD and youth pregnancy prevention in USA, available at http://www.cdc.gov/.2011.

[12] The National Campaign to prevent youths and unplanned pregnancy. Fast facts: Youth sexual Behavior and contraceptive use : Data from Youth risk behavier survey of USA. June 2010.

[13] G/Selassie G, Deyessa N, Tesfaye G: Intention to use condom among students in Agena preparatory school, Guraghe Zone, Ethiopia: with the application of health believe model. Archives of Public Health 2013. 71(23).

[14] Gavin L, Galavotti C, Dube H, Mcnaghaten MN, Murwiwa M, Khan R, Stlouis M: Factors associated with HIV infection in adolescent females in Zimbabwe. J Adolescent Health 2006. 39(e 596): p. 11-18.

[15] Federal HIV/AIDS prevention and control office: Multisectoral HIV/AIDS responce : anual monitoring and evaluation report. 2008-2009.

[16] Chapman R, White RG, Shafer LA, Pettifor A, Mugurungi O, Ross D, Pascoe S, Cowan FM, Grosskurth H,Buve A: Do behavioral difference help to explain variation in HIV prevalence in adolescents in Sub - Saharan Africa? Tropical Med Int Health, 2010. 15: p. 554-556.

[17] Adefoye AS,Abiona TC, Balagon JA, Lukosa DM: HIV sexual behavior and perception of risk among college students. Implication for planning intervention. BMC Public Health, 2009. 9: p. 281.

[18] Abebe M, Tsion A, and Netsanet F: Living with parents and risky sexual behaviors among preparatory school students in Jimma zone, South west Ethiopia. Afr Health Sci. , 2013. 13(2): p. 498-506. 
[19] Tura G, Alemseged F, and Dejene S: Risky Sexual Behavior and Predisposing Factors among Students of Jimma University, Ethiopia. Ethiop J Health Sci. , 2012. 22(3): p. $170-80$.

[20] Fentahun $\mathrm{N}$ and Mamo A: Risky sexual behaviors and associated factors among male and female students in Jimma Zone preparatory schools, South West Ethiopia: comparative study. Ethiop J Health Sci, 2014. 24(1): p. 59-68.

[21] Negeri, E.L., Assessment of risky sexual behaviors and risk perception among youths in Western Ethiopia:the influences of family and peers: a comparative cross-sectional study. BMC Public Health, 2014. 14:301.

[22] Biddlecome A, Awusabo-Asare K, and Bankole A: Role of parents in adolescent sxual actictivity and contraceptive use in four African countries. International perspect sex reproductive Health, 2009. 35: p. 72-81.

[23] Di clemente RJ, Wingood GM, Crosby R, Sionean C, Cobb BK, Hamington K, Davies S, Hook EW, :Parental monitoring, association with adolescents risk behavirs. J pediatrics 2001. 107: p. 1363-1368.

[24] Molla M, Berhane Y, and Lindjorn B: Traditional values of virginity and sexual behavior in rural Ethiopian youth. Med J BMC Public Health, 2008. 8(9).

[25] Podhisita C, Xenos $\mathrm{P}$, and Varangrat A: The risk of premarital sex among Thai youth: individual and family influences. East-west Center Working Papers, Population Series, 2001. 5(25): p. 108-5.

[26] Derese A, Seme A, and Misganaw C: Assessment of substance use and risky sexual behaviour among Haramaya University Students, Ethiopia. Science Journal of Public Health, 2014. 2(2): p. 102-110.

[27] Whitaker DJ and Miller KS: Parent adolescent discussion about sex and condom: Impact on peer ifluence of sexual risk behavier. J Adolescent 2000. 15: p. 251-273.

[28] Hampton MR, Mcwatters B, Jeffery B, Smith P: Influence of teen perception of parental disapproval and peer behavior on their initiation of sexual intercourse Can J Hum Sex 2005, 2005. 14(3): p. 105.

[29] Chai P: Parenting process and peer influence in the context of sexual risk behavior among young adults. J popular Soc Stud, 2007.

[30] Centers for Disease Control and Prevention.Youth risk behavior surveillance--United States, 2011. Morbidity and Mortality Weekly Report, 61(4). Retrieved from http://www.cdc.gov/mmwr/pdf/ss/ss6104.pdf.2012.

[31] Kebede D, Alem A, Mitike G, Berhane F, Bebe Y: Khat and alcohol use and risky sex behavior among in-school and out-of-school youths in Ethiopia. BMC Public Health, 2005. 5: p. 109.

[32] Shelia C: Parents, peers, and pressures: identifying the influences on responsible sexual decision-making. Adolescent Health, 2001. 2(2).

[33] Metzler CW, Noell J,Biglan A ,Ary D, Smolkowski K: The social context for risky sexual behavior among adolescents. Journal of Behavioral Medicine, 1994. 17: p. 419-438.

[34] Legesse E :Assessmnet of sexual behavior, attitude and risk perception about HIV/AIDS among out-of-school youths, Ilu-Abba-Bora Zone, Western Ethiopia. STAR journal of Wollega University, 2012. 1(2): p. 18-30.

[35] Oljira L, Berhane Y, and Worku A : Pre-marital sexual debut and its associated factors among in-school adolescents in eastern Ethiopia. BMC Public Health, 2012. 12: p. 375.

[36] Taffa N, Klepp K.I, Sundyby J, Bjune G: Psychosocial determinants of sexual activity and condom use intention among youth in Addis Ababa, Ethiopia. . International Journal of STD and AIDS, 2002. 13(10): p. 714-719.

[37] Schantz K: Substance Use and Sexual Risk Taking in Adolescence, in ACT youth center of excellenceJuly 2012, A collaboration of Cornell University, University of Rochester, and New York State Center for School Safety. 